\title{
Supporting Mobile Work Processes in Logistics with Wearable Computing
}

\author{
Ingrid Rügge \\ Mobile Research Center \\ University of Bremen, c/o BIBA \\ Hochschulring 20 \\ 29359 Bremen, Germany \\ $+494212185639$
}

rue@biba.uni-bremen.de

\author{
Carmen Ruthenbeck, \\ Jakub Piotrowski, \\ BIBA GmbH \\ Hochschulring 20 \\ 29359 Bremen, Germany \\ $+494212189792$
}

rut, pio@biba.uni-bremen.de mei, boe@biba.uni-bremen.de

\author{
Christian Meinecke, \\ Felix Böse \\ BIBA GmbH \\ Hochschulring 20 \\ 29359 Bremen, Germany \\ $+494212189788$
}

\begin{abstract}
Logistics is a very dynamic and heterogeneous application area which generates complex requirements regarding the development of information and communication technologies (ICT). For this area, it is a challenge to support mobile workers on-site in an unobtrusive manner. In this contribution, wearable computing technologies are investigated as basis for a "mobile worker supporting system" for tasks at an automobile terminal. The features of wearable computing technologies are checked against the requirements of the application area to come to an usable and acceptable mobile solution in an user-centred design process.
\end{abstract}

\section{Categories and Subject Descriptors} J.2 J.7 K.4.3.

\section{General Terms}

Design, Human Factors

\section{Keywords}

Wearable Computing, Mobile Usability, User-Centred Design, Mobile Work Processes, Autonomous Control, Logistics.

\section{INTRODUCTION}

Until now, planning and control of logistic processes are generally executed by centralized logistics systems, which cannot cope with high requirements for flexible order processing due to increasing dynamics and complexity. The use of the RFID (Radio Frequency Identification) technology, wearable computing solutions, and other innovative ICT become more interesting for all participants in logistics. These mobile technologies can increase the transparency of logistical processes, e.g. current stock information in production systems or actual storage positions of vehicles at automobile terminals for a better planning reliability, better access and a higher quality of information. They can support an adapted information flow to the needs of a mobile executive worker, e.g. during the outdoor maintenance of wind turbine generators (WTG), or the indoor maintenance of large passenger aircrafts [1] or for outdoor maintenance in general [2,3].

But the development of wearable computing solutions has not reached the level of applicable products until now. One reason is the lack of usability and acceptance of the proposed mobile solutions. To overcome the weaknesses of the available approaches and prototypes, methodological changes of the design process are proposed which focus on the specific features of Copyright is held by the author/owner(s).

MobileHCI'09, September 15 - 18, 2009, Bonn, Germany. ACM 978-1-60558-281-8. mobile work processes and the properties of wearable technologies and tools [4]. A "mobile worker supporting system" for logistics has to fulfil several specific requirements.

\section{Characteristics of Wearable Computing Solutions}

To support "mobile work processes beyond desktop work" [4] with mobile ICT, developments on different levels are necessary. The most important level for acceptance reasons is the personal on body - technological support of the mobile worker which can be realized with so called wearable computing technologies. The basic idea is as follows [5]: Wearable computing systems integrated with clothing (short "Wearables") support their users in an unobtrusive way. They allow users to perform their primary tasks with the assistance of a computer, but without cognitive overload. Explicit interactions with Wearables are minimised, therefore the worn system must recognise the current environment and the work situation of a user by integrated sensors. When focussing on the interaction between the user, the system, and the environment, the difference between mobile and wearable computing becomes obvious. In conventional mobile systems the design of the interaction is based on the desktop or the telephone metaphor. To use the system, the user needs to pay attention to the interface. An (idealistic) Wearable allows the user to interact with the system and the environment simultaneously.

\section{Requirement Analysis for "Mobile Work Processes" in Logistics}

The development of wearable computing solutions needs analyzing the environment, the business process, the technologies, and also the movement and bodily conditions of the user under the perspective of mobility and wearability. "Work activities" are differentiated into work processes which are performed at a desk or a stationary workplace, and those which are performed in motion. The later are called "mobile work processes" [4]. The centre is always the mobile working person. Mobile work processes have some common characteristics: performed in motion, at different locations, or on varying and big or extensive objects. It is characteristic for mobile work processes beyond desktop work that the user's primary task and therefore her attention is focused on the real world [4]. Furthermore, most mobile work processes are embedded in a more complex work process, which implies a certain level of autonomy of all entities (men, artefacts, and infrastructure) and requires a high degree of communication and cooperation between them. 
This contribution focuses on mobile work processes in logistics. The goal is to create a "mobile worker supporting system", which enables the user to perform her actual task efficiently, autonomously and without being bothered or distracted by a computer. Based on the analysis of operational processes, several system requirements for the hard- and software system have been derived [6]. Functional requirements are referring to the relevant workflows while technical requirements relate to technological aspect of the technical implementation with main focus on hardware and middleware. Aspects like safety at work or data security are addressed by safety requirements. User requirements relate to aspects of usability and acceptance. Functional requirements will be introduced below in the next chapter with regard to the considered scenario of vehicle management.

The main technical requirements are operation time, robustness and shock resistance, computing power and easy cleaning. Further there is a need to design the Wearbles to be robust and shock resistant to avoid damage in case of dropping. The computer power has to guarantee short response times of executed commands to reduce waiting times in the workflow. Aspects like data security or safety are addressed by the safety requirements. Today, the electromagnetic radiation is often discussed in case of using mobile or wearable technologies. Several values e.g. according to DIN61000-3 have to be limited to guarantee minimum of radiation [7]. In most cases, there is a need to implement a communication between the Wearable and a logistics backend system. Operational reliability has to be guaranteed by e.g. intermediate data storage to protect against power blackouts.

User requirements like the design of the graphical user interface, physical dimensions of the Wearable, keyboard design and display quality have direct influence on the user's acceptance. Easy usage and cleaning is relevant for the user interface. In case of using a wearable display the font size has to be defined to a viewing distance of $400 \mathrm{~mm}$. To allow a good readability in darkness the wearable keyboard should be illuminated. To reach a high user acceptance the weight of the Wearable including the power supply should not be more than $1400 \mathrm{~g}$. Wearable displays allow in most cases a view angle of $20^{\circ}$ to $40^{\circ}$ (in accordance to ISO 13406-2/7.2) and an individual setting for contrast and brightness [8, 9]. As mentioned above functional requirements as well as additional technical requirements are dependent on the considered scenario. Based on the scenario of vehicle management these requirements are specified as follows.

\subsection{Vehicle Management Process}

The main business processes at automobile terminals are transport of vehicles from a ship, truck or train to the automobile terminal, storage of vehicles and technical treatment as well as delivery to an automobile dealer. Efficient vehicle management in automobile logistics networks requires knowledge about the actual positions of all vehicles at any time [7]. To execute the logistics processes like vehicle identification, localisation or storage allocation there is a need for special technical and functional requirements.

Based on the concept of a decentralized controlled storage management of vehicles, functional requirements referring to relevant handling processes of vehicles can be derived [10]. As mentored above the vehicle identification via vehicle identification number (VIN) is necessary. The exact position of vehicles at the terminal area is needed to realize a fast, flexible and orderly storage management. The wearable application has to support the handling employee by user guides or wizards to avoid misunderstandings. At the moment, the prototype of a "smart jacket" as an implementation of a "mobile worker supporting system" is under construction. In the next step it will be evaluated under all mentioned perspectives.

\section{ACKNOWLEDGMENTS}

This research is partly supported by the German Research Foundation (DFG) as part of the Collaborative Research Centre 637 "Autonomous Cooperating Logistic Processes - A Paradigm Shift and its Limitations” at the University of Bremen.

\section{REFERENCES}

[1] Nicolai, T.; Sindt, T.; Kenn, H,; Witt, H. 2005 Case Study of wearable Computing for Aircraft Maintenance in Proc. of IFAWC’05, Zürich, VDE Verlag, pp.97-110.

[2] Bass, L.; Siewiorek, D.; Bauer, M.; Casciola, R.; Kasabach, C.; Martin, R.; Siegel, J.; Smailagic, A.; Stivoric, J. 2001 Constructing Wearable Computers for Maintenance Applications in Barfield, W.; Caudell, Th. (Eds.), Fundamentals of Wearable Computers and Augmented Reality. Lawrence Erlbaum: Mahwah, NJ, London, pp.663-713

[3] Boronowsky, M.; Nicolai, T.; Schlieder, C.; Schmidt, A. 2001 Winspect: A Case Study for Wearable ComputingSupported Inspection Tasks in ISWC'2001, October 8-9, Zürich. IEEE, pp.163-164

[4] Rügge, I. 2007 Mobile Solutions - Einsatzpotenziale, Nutzungsprobleme und Lösungsansätze. DUV/Teubner Research: Wiesbaden.

[5] Herzog, O.; Boronowsky, M.; Rügge, I.; Glotzbach, U.; Lawo, M. 2007 The Future of Mobile Computing: R\&D Activities in the State of Bremen in Internet Research, Vol. 17, Issue 5, 2007, Special issue: TERENA conference 2007, pp.495-504

[6] Böse, F.; Piotrowski, J.; Windt, K. 2005 Selbststeuerung in der Automobil-Logistik in Industriemanagement, 20 (2005) 4, 37-40.

[7] DIN 61000-3-2 (2006). Elektromagnetische Verträglichkeit (EMV) Teil 3-2: Grenzwerte - Grenzwerte für Oberschwingungsströme; Deutsche Fassung EN 61000-3-2:2006. Berlin: VDE Verlag.

[8] Böse, F.; Piotrowski, J.; Scholz-Reiter, B. 2009 Autonomously controlled storage management in vehicle logistics - applications of RFID and mobile computing systems in International Journal of RT Technologies: Research an Application, Vol. 1, No. 1, Taylor \& Francis, pp 57-76

[9] ISO 13406-2 (2001). Ergonomic requirements for work with visual displays based on flat panels -- Part 2: Ergonomic requirements for flat panel displays. Geneva: ISO copyright office.

[10] Scholz-Reiter, B.; Windt, K.; Kolditz, J.; Böse, F.; Hildebrandt, T.; Philipp, T.; Höhns, H. 2006 New Concepts of Modelling and Evaluating Autonomous Logistic Processes in Chryssolouris, G.; Mourtzis, D. (Eds), Manufacturing, Modelling, Management and Control 2004, IFAC Workshop Series, Amsterdam: Elsevier Science. 